\title{
CAPACITAÇÃO DA MÃO DE OBRA NA CONSTRUÇÃO CIVIL
}

Marcos Roberto Toron de Souza ${ }^{1}$

Frank Dieter Schulze ${ }^{2}$

\section{RESUMO}

A capacitação de mão de obra vem se mostrando cada vez mais indispensável para as empresas que disputam um espaço no mercado, principalmente no setor da construção civil, visto que houve um crescimento no volume de obras na cidade, porém, as quantidades de profissionais capacitados e qualificados para realizarem as diversas atividades não apresentaram o mesmo crescimento.

Palavras-Chave: Capacitação. Qualificação de Mão de obra. Construção civil.

\section{ABSTRACT}

The training of labor is proving increasingly indispensable for companies that compete for a market space, especially in the civil construction sector. Since there was an increase in the volume of works in the city, however, the number of professionals trained and qualified to carry out the various activities did not show the same growth.

Keywords: Training and qualification of labor. Civil Construction.

\section{INTRODUÇÃO}

Atualmente um dos principais problemas presentes nas empresas da construção civil tem sido a falta de mão de obra qualificada para a execução dos diversos serviços realizados em diferentes etapas das obras.

Devido ao crescimento que aqueceram a construção civil no Brasil, a

\footnotetext{
${ }^{1}$ Acadêmico do curso de Engenharia Civil da Universidade Alto Vale do Rio do Peixe (UNIARP).

2 Professor Orientador e docente do Curso de Engenharia Civil da Universidade Alto Vale do Rio do Peixe
} 
oferta por empregos nos seus diversos setores vêm aumentando consideravelmente, porém, a demanda não tem conseguido suprir esta oferta.

Cavalcante (2010) a elevação da exigência, por parte dos clientes, nos cumprimentos de entrega do produto final, com alta qualidade e nos prazos predeterminados, obrigam que as empresas busquem trabalhar com uma mão de obra cada vez mais qualificada, visando elevar seus níveis de produtividade e qualidade das atividades, reduzindo os gastos o máximo possível, para que estas possam se manter em um nível competitivo no mercado.

Partindo deste princípio, segundo Cavalcante (2004) as empresas devem adotar estratégias para que possam prestar seus serviços de forma diferenciada sempre visando o sucesso, o desenvolvimento da organização e resultados positivos, porém, para obter estes objetivos, a empresa deve trabalhar com duas ferramentas de suma importância: a qualificação e a motivação dos indivíduos.

Dentre as estratégias adotadas pelas empresas, podem-se citar as mudanças na tecnologia de construção (materiais, equipamentos, mão de obra, etc.), terceirização dos serviços e principalmente a capacitação da sua própria mão de obra. Que ponto a capacitação de mão de obra na construção civil torna-se um processo viável, eficiente e eficaz?

Deve ser analisada a melhor metodologia a ser aplicada neste processo para torná-lo o mais lucrativo possível (lucrativo tanto para a empresa em questão, quanto para o profissional que se capacita em determinada função, não esquecendo o mercado da construção civil, em geral).

O objetivo geral deste trabalho é apresentar uma metodologia que possibilite o planejamento e a execução de um programa de capacitação e qualificação de mão de obra, no próprio canteiro, aos operários da construção civil.

O objetivo específico é analisar o atual panorama da construção civil na cidade de Caçador-SC; Mostrar o que vem sendo realizado na cidade, para suprir a necessidade da mão de obra capacitada; Analisar os benefícios causados e as dificuldades que envolvem no emprego de programa de capacitação da mão de obra nas empresas da construção civil. 


\section{DESENVOLVIMENTO}

\section{HISTÓRIA DA CONSTRUÇÃO CIVIL}

Antes que conquistasse o prestígio e alcançasse o desenvolvimento que tem hoje, foi preciso que a construção civil percorresse um longo trajeto de seis mil anos, desde que o homem deixou as cavernas e começou a pensar numa moradia mais segura e confortável para a sua família. Já os templos, os palácios e os canais, que foram marcas registradas na Antiguidade, começaram a fazer parte da paisagem cerca de dois mil anos, depois do aparecimento das primeiras habitações familiares (RIBEIRO, 2011).

As primeiras obras civis no Brasil começaram na transição do século XIX para XX. Nos últimos 100 anos foram de transformações, as técnicas utilizadas foram: taipa (barro) de mão e taipa-de-pilão (socada), sendo a mão de obra escrava e do próprio morador (VIEIRA, 2008).

A indústria da construção civil está dividida em três subsetores: Edificações residenciais, realizados por empresas de grande, médio e pequeno porte; construção pesada, que objetiva a construção de infraestrutura de transportes, energia, telecomunicações e saneamento; e montagem industrial, responsável pela montagem de estruturas metálicas nos vários setores industriais, sistemas de geração de energia, de comunicações e de exploração de recursos naturais (VIEIRA, 2006).

A importância do subsetor de edificações que é responsável, segundo o IBGE por mais de $90 \%$ do número de estabelecimentos da construção civil e mais de $82 \%$ do total de empregos do setor construtivo. Um estudo do Banco Nacional de Desenvolvimento Econômico e Social - BNDES, realizado em 2007, indicava que a construção civil residencial iria liderar o ranking dos investimentos no Brasil, nos quatro anos seguintes, com praticamente metade do total a ser investido no país (HELENO, 2010).

A mão de obra da construção civil representa grande porcentagem no custo total da obra, além de influenciar diretamente em outras variáveis, como racionalização ou desperdício de materiais, antecipação ou atraso do cronograma, 
qualidade de execução, podendo causar elevação dos custos predeterminados da obra (LARA, 2005).

A demissão de um colaborador depende bastante do seu nível de satisfação na empresa, ou seja, operários insatisfeitos apresentam maiores probabilidades de serem desligados. Deste modo, se o operário observa que a empresa está investindo em sua qualificação, dá suporte para que possa trabalhar com maior eficiência e em um bom ambiente de trabalho, dificilmente este trabalhará em uma empresa concorrente, diminuindo desta forma a rotatividade do setor (FERREIRA, 2007).

\section{EXPECTATIVA DE CRESCIMENTO DA CONSTRUÇÃO CIVIL}

Segundo Castelo (2018), o aumento do PIB pode não acontecer se houver contingenciamento de recursos para projetos de infraestrutura, com a consequente paralisação das obras, que a previsão de um declínio menor no nível de emprego que nos anos anteriores. A diminuição esperada de cerca de 2,5\%, significa o corte de 81 mil vagas.

Segundo Manfredi (2008), os termos qualificação e formação profissional, são entendidos como a preparação de trabalhadores para fazer frente às demandas técnicas-organizacionais do mercado de trabalho, de modo a desempenhar uma determinada ocupação profissional.

A formação para a cidadania também é considerada um aspecto relevante para a capacitação do profissional do setor da construção civil. O processo educativo contribui para o desenvolvimento integral do ser humano, incentivando e educando para a prática da participação individual e coletiva (VIERA; ALVES, 2001).

\section{CERTIFICAÇÃO PROFISSIONAL}

O Serviço Nacional de Aprendizagem Industrial - SENAI é o que tem se voltado à construção civil. Ele apoia-se em comitês técnicos setoriais constituídos por especialistas do setor que elaboraram perfis profissionais (competência geral da qualificação profissional em foco, que segue o desdobramento num primeiro 
nível) de interesse, os quais permitem que se estabeleçam uma estrutura de oferta com base em perfis profissionais elaborados, que possibilitam definir conteúdos curriculares voltados à formação, à avaliação e à certificação de competências (SENAI, 2007).

Segundo o SENAI (2007), já desenvolveram oito perfis profissionais para o setor: Amador; Carpinteiro de Formas; Eletricista Instalador Predial de Baixa Tensão; Encanador Instalador Predial; Instalador Predial de Tubulações de Gás Combustível;

Mestre de Obras; Pedreiro e Pintor de Obras.

\section{PARTICIPAÇÃO DAS MULHERES}

Uma ação do Governo Federal também como projeto pioneiro "Mão na Massa", no Rio de Janeiro, onde são oferecidos cursos profissionalizantes com o intuito de garantir oportunidades às mulheres na indústria da construção. $\mathrm{Na}$ qualificação profissional as participantes além das aulas e do diploma, recebem equipamento de proteção individual e um kit de ferramentas para iniciar seus serviços após a qualificação (IMOB, 2018).

Segundo Gomes (2018), todos os projetos de conhecimento de inclusão de mulheres têm foco na qualificação, onde elas conseguem entrar no setor da construção civil já qualificadas e com uma profissão. Quem já reconhece que nos níveis administrativos e nos níveis gerenciais a presença da mulher é uma realidade já há muito tempo nas indústrias, falta agora no nível operacional.

O número de trabalhadoras no setor da construção vem crescendo no país, apesar de a crise que se instalou nos últimos anos. Segundo RAIS, em 2006, cerca de 108 mil mulheres integravam o setor, de um total de 1.438 milhão de trabalhadores. Em 2016, elas já ocupavam mais de 219 mil vagas, de um total de cerca de 2.122 milhão, uma participação de 10\% no mercado de trabalho. São serventes, carpinteiras, ajudantes de obra, pedreiras, soldadoras, técnicas em segurança do trabalho e engenheiras, têm condições de realizar as tarefas com tanta competência quanto os trabalhadores (CBIC, 2018). 
APLICAÇÃO DE ANDRAGOGIA NA CONSTRUÇÃO CIVIL

O termo Andragogia foi sugerido pelo professor alemão Alexander Kapp, em 1833, caindo em desuso. Mas em 1921 ele reaparece no relatório de Rosenstok, onde é alertado que a educação de adultos necessita de professores, métodos e filosofias diferenciadas (CHACON FILHO, 2007).

Alguns pesquisadores têm visto Andragogia como uma teoria de educação de adultos, enquanto outros a vê como uma abordagem, um conjunto de princípios, um conjunto de suposições ou uma orientação para a prática da educacional. Contribui em muito para a educação de adultos (CHAN, 2010).

\section{MESTRE DE OBRAS}

Com os valores das demandas, se iniciou a elaboração do curso de mestre de obras com o objetivo de preparar profissionais para supervisionar atividades desenvolvidas no canteiro de obras, participarem de planejamento executivo e gerenciar equipes de trabalho, de acordo com normas e procedimentos técnicos de qualidade, segurança, higiene e saúde (SCHULER, 2018).

A regulamentação da profissão diferentemente da (CLASSIFICAÇÃO BRASILEIRA DE OCUPAÇÕES - CBO), é realizada por lei cuja apreciação é feita pelo Congresso Nacional, por meio de seus deputados e senadores, submetida à sanção do presidente da república. A CBO é uma ocupação e não uma de regulamentação profissões (CASSOL, 2017).

Com este curso o aluno vai estar preparado para supervisionar as etapas de execução em canteiro de obras e participar na execução do planejamento da obra, criando condições para garantir a qualidade, segurança no trabalho e a preservação ambiental (SCHULER, 2018).

\section{Primeiros Socorros}

A presença do kit de primeiros socorros é importante em qualquer ambiente de trabalho e é fundamental na construção civil. Esse é um ambiente extremamente propício a acidentes de qualquer ordem, sejam eles mais superficiais ou mais graves (BUGNOTTO, 2018). 
Além do kit é necessário treinamento para que realizem os procedimentos em casos de emergência. Dessa forma saberão o que fazer, garantindo que por falta de conhecimento, não realizem qualquer tipo de ação que agrave o caso.

Definimos ainda como o primeiro atendimento realizado a uma pessoa que sofreu algum trauma, lesões ou mal súbito, como as primeiras providências tomadas no local do acidente (BUGNOTTO, 2018).

\section{Segurança no Trabalho NR-18}

Esta norma tem seus principais objetivos: garantir plenamente a saúde e a integridade física dos trabalhadores da construção civil; criar e operar mecanismos para prever riscos que derivam do processo de execução de obras em canteiros; determinar medidas de proteção e prevenção que sejam capazes de evitar ações e situações de risco; aplicar as técnicas de execução pertinentes em todas as atividades e que reduzam riscos de doenças e acidentes (MTE, 1978).

A norma regulamentadora também obriga o uso de colete ou tiras refletivas na região do tórax e costas quando o trabalhador estiver a serviço em vias públicas, sinalizando acessos em canteiro de obras e frentes de serviços ou em movimentação e transporte vertical de materiais. A sinalização de segurança em vias públicas deve ser dirigida para alertar os motoristas, pedestres e em conformidade com as determinações do órgão competente.

\section{Leitura e Interpretação de Projetos}

O mestre de obra fica responsável para que todas as atividades no canteiro da obra e fica em sua importância a organização. Como característica fundamental de um bom profissional a iniciativa e o primeiro passo para que a obra se desenvolva do início ao fim (CASSOL, 2017).

Nas suas habilidades procura utilizar corretamente os instrumentos de medição, saber as diferenças nas unidades de medidas. O profissional fica responsável em interpretar os documentos para execução da obra, como base nos cálculos matemáticos fica em seu critério a quantidade de materiais a ser necessário para a obra. O projeto que chegar em suas mãos interpretar 
corretamente.

\section{Planejamento dos Sistemas Construtivos}

Em alguns setores o começo ocorre tudo certo, mas vem sofrendo mudanças à medida que os empreendimentos percebem a necessidade do planejamento para a adequação de prazos e custos (MATTE, 2018).

O planejamento e o controle permitem uma visão real da obra, servindo de base confiável para as decisões que deverão ser tomadas. Pode trabalhar de forma mais assertiva com as folgas das atividades e tomar decisões importantes como nivelar recursos, alocação de determinados equipamentos.

Os sistemas construtivos resumem-se na execução das atividades diversas com envolvimento dos recursos como materiais, ferramentas, máquinas e pessoas para o desenvolvimento das mesmas. Dividimos os sistemas construtivos em três grupos principais: tradicional, convencional e industrial (MATTE, 2018).

No ramo da construção civil, existem diversos sistemas construtivos para a execução de uma edificação. O método mais utilizado é a alvenaria convencional, porém, novas tecnologias estão aparecendo e começando a ser utilizadas. Os que predominam são: alvenaria convencional, alvenaria estrutural, steel frame, wood frame e paredes de concreto (CASSOL, 2017).

\section{Gestão do Processo Construtivo}

Neste caso, a gestão enfatiza a capacidade de os mecanismos de fluxo de trabalho para controlar fluxos de processos, medir automaticamente processos e educar e organizar gerentes para que eles façam a gestão de processos de forma eficaz (SANTOS, 2018).

Gestão de obras talvez seja a que necessita de maior vivência no setor e entendimento dos processos de cada etapa do projeto, pois serão esses profissionais quem devem resolver os problemas que aparecem no dia a dia das obras (SANTOS, 2018).

Não podemos confundir definições de processos e padrões, com falta de personalização dos projetos. Todo projeto pode ser diferenciado, pode ser 
desenvolvido para atender uma necessidade específica, com medidas especificas, informações que podem variar de projeto a projeto, ao alterar as informações de cada variável do sistema (CASSOL, 2017).

Desenvolvimento de condições que permitam a reformulação das questões diante de eventuais impasses e pela disposição das partes ou do condutor do processo a abordar e quaisquer que estejam influenciando a relação das partes (CALDAS, 2017).

\section{Gestão de Pessoas}

A gestão de pessoas começa pela grande oferta de profissionais no mercado com qualificação abaixo do esperado. A engenharia civil tem encontrado muitos entraves relacionados aos recursos humanos. Principalmente as pequenas e médias empresas, uma vez que os profissionais mais qualificados e destacados são rapidamente captados pelas companhias de grande porte, que oferecem salários e benefícios muitos vezes mais atraentes (MARQUES, 2018).

Os programas de gestão de pessoas e menos adquiridos por donos de pequenas empresas. O investir em pessoas não é muito popular nas empresas brasileiras, uma dúvida geral é se eu investir nos meus funcionários e eles pedirem demissão? (MARQUES, 2018).

O capital humano é um dos recursos mais importante da empresa; sem os colaboradores não podem existir prestação de serviços e nem produção. A pressão, a competitividade, as diferenças religiosas, sociais e étnicas podem promover estresse e conflitos entre colaboradores (MARQUES, 2018).

\section{ANÁLISE DOS DADOS E RESILTADOS}

\section{ENSINO PROFISSIONALIZANTE}

As práticas laboratoriais pensam uma integração por demonstração ou aplicação de conhecimentos teóricos já adquiridos. Os estágios de final de curso, além de partirem dos mesmos princípios, não oferecem oportunidade pedagógica 
de integração. É o mundo do trabalho (CARVALHO, 2011).

O objetivo de compreender como o ensino profissionalizante surge no Brasil, engloba a necessidade do estudo da inserção da educação no país, destacando as primeiras iniciativas para o incentivo de instalação de escolas, as características dos alunos e a estrutura das políticas públicas de educação.

Souza (2008), a discussão sobre o que seria ensinado para o povo era debate político, buscando solucionar a questão da formação de todos os cidadãos, selecionando saberes da época dentro da cultura literária, científica, técnica, artística e doméstica, conhecimentos considerados úteis para o favorecimento de nova visão de mundo e modificação de hábitos, criando novos valores da modernidade. Quais seriam então esses conhecimentos de maior valor? A premissa definida foi elencar por ordem de importância dos principais gêneros que constituem a vida do homem, sendo assim o resultado: 1ㅇ) atividades que diretamente contribuíram para a conservação própria do indivíduo; 2ํ) atividade que, assegurando as coisas necessárias à vida, contribuíam indiretamente para a conservação própria; 3 ㅇ) atividades que tinham pôr fim a educação e a disciplina dos filhos; 4) atividades relativas ao procedimento social e às relações políticas entre as pessoas e por último, 5ㅇ) atividades que procedem o resto da vida consagrada à satisfação dos gostos e dos sentimentos.

A organização do modelo unitário era estabelecida por um professor que ministrava o ensino para alunos de diferentes níveis de adiantamento, todos ficavam no mesmo ambiente e o espaço escola não era um local construído para a finalidade, muitas vezes o ensino era transmitido na casa do professor. As escolas graduadas utilizavam do método simultâneo, onde os alunos eram reunidos em pequenos grupos de acordo com o grau de conhecimento. Todos os alunos daquele grupo deveriam estudar os mesmos conteúdos, e realizar as mesmas atividades. A dificuldade para os professores era de como separar os grupos e quais conteúdos ministrar nas deferentes faixas etária. (SOUZA, 2006).

As transformações escolares ocorrem nas décadas finais do século XIX e início do século XX no Brasil. Entre 1892 e 1896, dispositivos legais consubstanciaram a reforma da instrução pública, articulando os três níveis de ensino - o primário, o secundário e o superior. O curso primário foi fixado em 8 
anos de duração, dividido em dois cursos: o preliminar com 4 anos de duração até 12 anos de idade, sendo obrigatório, porém direcionado para a aprendizagem de leitura, escrita, cálculo e rudimentos das ciências naturais e sociais e o complementar com também 4 anos de duração, porém direcionado para a ampliação de cultura geral. A publicidade à escola no meio popular deveria ser efetuada, e o meio encontrado foi a praticada de festas escolares e das comemorações cívicas. (SOUZA, 2008).

Carvalho (2011), novas concepções são veiculadas sobre o ensino profissionalizante, com ênfase no manifesto dos pioneiros da educação nova, de 1932, a crítica de Anísio Teixeira sobre a divisão do sistema educacional brasileiro entre o trabalho manual e o trabalho intelectual, que revela de um lado as escolas primárias, escolas normais e escolas profissionais e agrícolas, focadas na formação prática, utilitária para o ensino primário e as ocupações manuais ou os ofícios, as escolas secundárias, escolas superiores e universidades, direcionadas na formação do homem culto ou não práticos.

Hoje a oferta do ensino profissionalizante encontra-se desde o ensino Pronatec, Escolas Técnicas, Escola de Qualificação Profissional, também o SENAI subsidiado pelos industriais e governo através do Fundo de Amparo ao Trabalhador. Cada um desses possui as suas peculiaridades para recrutamento, desde exames como Vestibulinho, comprovação de renda ou até mesmo uma simples inscrição. As principais características ainda continuam sendo de cursos rápidos, exigência de práticas embora substanciadas de aprendizado das relações humanas e teorias do saber. A população ainda atendida em maior escala são pessoas em vulnerabilidade. A preocupação nas instituições de Ensino Profissionalizante sempre foi a construção do Perfil Profissional para uma melhor adequação do plano de curso, buscando sempre a atualização com o mercado referente as novas técnicas de trabalho e também tecnologia. Salientamos que hoje essas instituições respondem por níveis de qualidade de ensino e evasão escolar, os aspectos são relevantes, embora exista questionamentos aos suportes de infraestrutura adequada ao curso e principalmente ao corpo docente. A observação da amplitude do ensino profissionalizante parece positiva, mas ainda uma grande parcela da população brasileira não encontra subsídio para frequentar uma escola 
de ensino fundamental, quem dirá uma escola profissionalizante.

SENAI

Em 1954 o SENAI em São Paulo já havia se expandido tanto que a comunicação entre 600 funcionários já se tornava difícil. Passando por dificuldades financeiras entre os anos de 1947 e 1949 a palavra de ordem mudou para trabalho em profundidade, alternando de postura administrativa por necessidade em se manter, chegando ao ponto de se reestruturar os métodos de ensino. O SENAI se estabiliza ao longo do tempo e se mantém até os dias de hoje, oferecendo diversos cursos, desde cursos de aprendiz, para nível operacional, cursos técnicos e graduação.

Os cursos que são oferecidos é feito uma análise para ver qual o público a ser atingido, é enviado um responsável nas construtoras e é feito um estudo na empresa para ver qual o profissional está precisando capacitar. Com isso, todos os dados obtidos a instituição faz o lançamento dos cursos. Já o curso mestre de obras e muito avançado e atinge o profissional que possuem boa escolaridade (informação verbal) ${ }^{3}$.

\section{INSTITUTO FEDERAL DE SANTA CATARINA}

Em 1937, por meio da Lei no 378, a instituição mudou de nome e status, passando a chamar - se Liceu Industrial de Florianópolis. Em 1965 mudou novamente de nome, passando para Escola Industrial Federal de Santa Catarina.

A partir de 1968, começou o processo de extinção gradativa do curso Ginasial, por meio da supressão da matrícula de novos alunos na primeira série. 0 objetivo era especializar a escola em cursos técnicos de segundo grau (atual ensino médio).

O Instituto Federal de Santa Catarina conta então com 22 campi em 20 cidades de Santa Catarina por meio dos quais busca ser uma instituição de excelência na educação profissional, científica e tecnológica fundamentada na

\footnotetext{
${ }^{3}$ Notícia fornecida por Carlos Schuler no Serviço Nacional de Aprendizagem Industrial, em Caçador, em Março de 2019.
} 
gestão participativa e na dissociabilidade entre ensino, pesquisa e extensão.

Na unidade de Caçador, para os cursos oferecidos é necessário a criação de projetos, e é mandado para reitoria lá de Florianópolis, e se for aprovado deve ser distribuídos para todas as unidades e precisam ser desenvolvido por um professor do campus da instituição. E atualmente para formação na área da construção civil, não possui nenhum curso, na unidade de Caçador (informação verbal) $)^{4}$.

\section{EMENTA DO CURSO}

O curso mestre de obras pretende atender a essa demanda de profissionais, oferecendo formação na área de supervisão e controle de obras. Assim, o aluno terá a chance de conhecer diversas áreas da construção civil e ainda desenvolver-se nas áreas de liderança e trabalho em equipe, que são indispensáveis para o desempenho adequado das funções deste profissional (PINTO, 2018).

O mestre de obras precisa de uma formação sólida em diversas áreas, as dominado para que não haja prejuízos em seu desempenho e para facilitar o aprendizado e incluir a maior quantidade possível de informações sobre a construção civil. O aluno poderá conhecer de forma geral os serviços realizados em uma obra e os itens mais importante com relação a cada um deles, tendo a oportunidade de aprender outros tópicos que são parte fundamental de sua formação para o excelente exercício da profissão (PINTO, 2018).

Com o curso de formação de mestre de obras o aluno planeja uma obra do início ao fim, conhecendo todas as etapas da construção civil e colocando na prática como deve ser a liderança e o trabalho em equipe dentro do canteiro para superar as expectativas previstas no cronograma e o orçamento da obra. Preparese para se envolver no mundo da construção e conhecer na prática assuntos como logística e instalação do canteiro de obras, sistemas preliminares e estruturais, desde a fundação até o acabamento, executando o check list da entrega de obra e aplicando técnicas. De qualidade no canteiro para que possa fazer de cada

\footnotetext{
${ }^{4}$ Notícia fornecida por Bruno Vieira no Instituto Federal de Santa Catarina - IFSC, em Caçador, em Março de 2019.
} 
profissional um mestre de obras diferenciado (PINTO, 2018).

Quadro 01: Matriz Curricular

\begin{tabular}{l|l|l|l}
\hline \multirow{2}{*}{ Unidade Curricular } & \multicolumn{2}{l}{ Carga Horária } & \multicolumn{2}{l}{ Total } \\
\cline { 2 - 4 } & Á Distância & Presencial & 30 \\
\hline Primeiros Socorros & - & 30 & 30 \\
\hline Segurança do Trabalho NR-18 & - & 30 & 20 \\
\hline Meio Ambiente & - & 20 & 48 \\
\hline Leitura e Interpretação de Projetos & - & 48 & 60 \\
\hline Planejamento na Construção Civil & - & 60 & 60 \\
\hline Sistemas Construtivos & - & 60 & 60 \\
\hline Gestão do Processo & - & 60 & 60 \\
\hline Processo Construtivo & - & 60 & 32 \\
\hline Gestão de Pessoas & - & 32 & 400 \\
\hline TOTAL & - & 400 & \\
\hline
\end{tabular}

Fonte: SENAI / INSTITUTO FEDERAL(2019)

\section{CONCLUSÃO}

O presente trabalho tratou da implementação de um curso de mestre de obras, o qual possibilitaria a capacitação e qualificação de pessoas da construção civil. O tema em questão ainda não foi muito abordado e existem poucos trabalhos que tratem do assunto. Portanto, para a realização deste, foi feito uma entrevista com o coordenador do Serviço Nacional de Aprendizagem Industrial-SENAI, com o intuito de desenvolver e aprimorar uma metodologia do curso, para que os objetivos fossem alcançados.

A eficiência deve ser adquirida através de acompanhamentos na sala de aula e em laboratório, além disso, outro fato importante a ser frisado é que deve ser aproveitado o tempo ao máximo do curso, devido ao fato dos alunos seguirem todas as técnicas construtivas presentes nos manuais técnicos.

A eficácia do projeto deve ser observada no acompanhamento do curso, pois o período de início e fim das atividades é o suficiente para que não haja atrasos nas aulas. 
Após todos estes fatos poderia afirmar que o objetivo do curso será alcançado, porém, deve (haver) continuidade neste processo, para que seja possível um aprimoramento da metodologia, pois este é somente um projetopiloto.

\section{REFERÊNCIAS}

BRESSIANI, Lucia; ROMAN, Humberto; Ramos. A Utilização da Andrologia em cursos de Capacitação na Construção Civil. Disponível em:

http://dx.doi.org/10.1590/0104-530x2245-17. Acesso em: 12 out. 2018.

CALDAS, Deyne; Bezerra, Leitura e Interpretação de projetos. Natal: SENAI/RN, 2011.

CASSOL, Adriana. Educação Profissional - Mestre de Obras. Caçador: SENAI/SC, 2017.

CASTELO, Flávio; Branco. Sondagem Industrial - Construção Civil - Falta de trabalhadores qualificados. Disponível em: < http://www.cbicdados.com.brmedia/anexos/Sond-jul18>. Acesso em: 12 out. 2018.

FERNANDEZ H. M. Evitando a falência - Garanta o sucesso de seu negócio. São Paulo: Editora leditora, 2003 FERREIRA, Rita; Cristina. Processo Construtivo.

Disponível em: <https://www.aecweb.com.br/cont/m/rev/processoconstrutivo_6588_3_0>. Acesso em: 14 out. 2018.

FREIRE, Paulo. Pedagogia Dialético de Aristóteles. São Paulo: Editora Brasiliense S. A, 2016.

GOMES, Ana. Como está a participação da mulher na construção civil. Revista IMOB, Rio de Janeiro, V.1, N.1, mar. 2018. Edição especial.

LOPES, Nathalia. Setor da Construção mantém expectativa de crescimento baixo em 2018. Revista Digital, São Paulo, V. 1, N.1, Jun. 2018. Edição Especial.

MARQUES, José; Roberto. Conceito e Definição de gestão de pessoas. 2018.

Disponível em: <https://www.jrmcoaching.com.br/blog/conceito-e-definicao-degestao-de-pessoas>. Acesso em: 15 out. 2018. 
MENDES, Henrique. A Construção civil e seu impacto no meio ambiente.

Disponível em: <https://www.todamateria.com.br/tudo-sobre-meio-ambiente>. Acesso em: 12 out. 2018.

PEREIRA, Caio. Principais tipos de sistemas construtivos utilizados na construção civil. Disponível em: <https://www.escolaengenharia.com.br/tipos-de-sistemasconstrutivos>. Acesso em: 13 out. 2018.

PINTO, David. Instituto da Construção formação profissional - mestre de obras. São Paulo: AKDK Editora, 2018.

PRODANOV, Cleber Cristiano; FREITAS, Ernani Cesar. Metodologia do trabalho científico: métodos e técnicas da pesquisa e do trabalho acadêmico. 2. ed. Rio Grande do Sul: Feevale, 2013.

RIBEIRO, Nelson; Porto. Contributo para a História da Construção no Brasil: Simpósio Nacional da História. Revista SINDUSCON. São Paulo, V.3, N.20, Jul. 2014.

SANTOS, Virgílio; Marques. Gestão de processos. Disponível em:

<https://www.fm2s.com.br/gestao-de-processos>. Acesso em: 13 out. 2018.

SILVA, Antônio. Segurança no Trabalho na Construção Civil: Uma Revisão

Bibliográfica. Revista Pensar Engenharia. Rio de Janeiro, V.1, N.1, jan. 2015. 